\title{
The Brown Dwarf Talking Blues
}

inspired by IAU Symposium 211

(to the accompaniment of Woody Guthrie's Talking Blues)

Soaking up the rays at Waikoloa,

Two years before two thousand four,

Pondering problems with nomenclature

Of heavenly orbs of tiny stature.

Brown Dwarfs ... Magenta Midgets ...

After dinner I attended a session, hoping to learn a useful lesson.

The big kahunas, and the Boss-man too delivered the opinion of the IAU. Gas Giants ... Sub-brown dwarfs ...

Things that fuse in the night are stars,

And orbiting them are planets like Mars.

Can't see those cause of their low mass,

So we argue about great balls of gas.

Free Floaters ... Superplanets ...

Observations show they're free in space,

Theory says they must have come from some place.

So what do you call that Jovian ball

Floating in space and not in thrall?

Substellar mass objects ... Plamos ...

Nature or nurture was the question to some,

Others just cared for the mass, by gum!

Political correctness carried the day:

Tally up the names in the papers, they say.

Mass-challenged stars ... russet runts...

If you ask me it doesn't make much sense

To hotly debate our ignorance.

Seems to me planets are really obscene...

When you see it you'll know it, if you get what I mean.

Damn Degenerates ...

F. M. Walter, 2002 


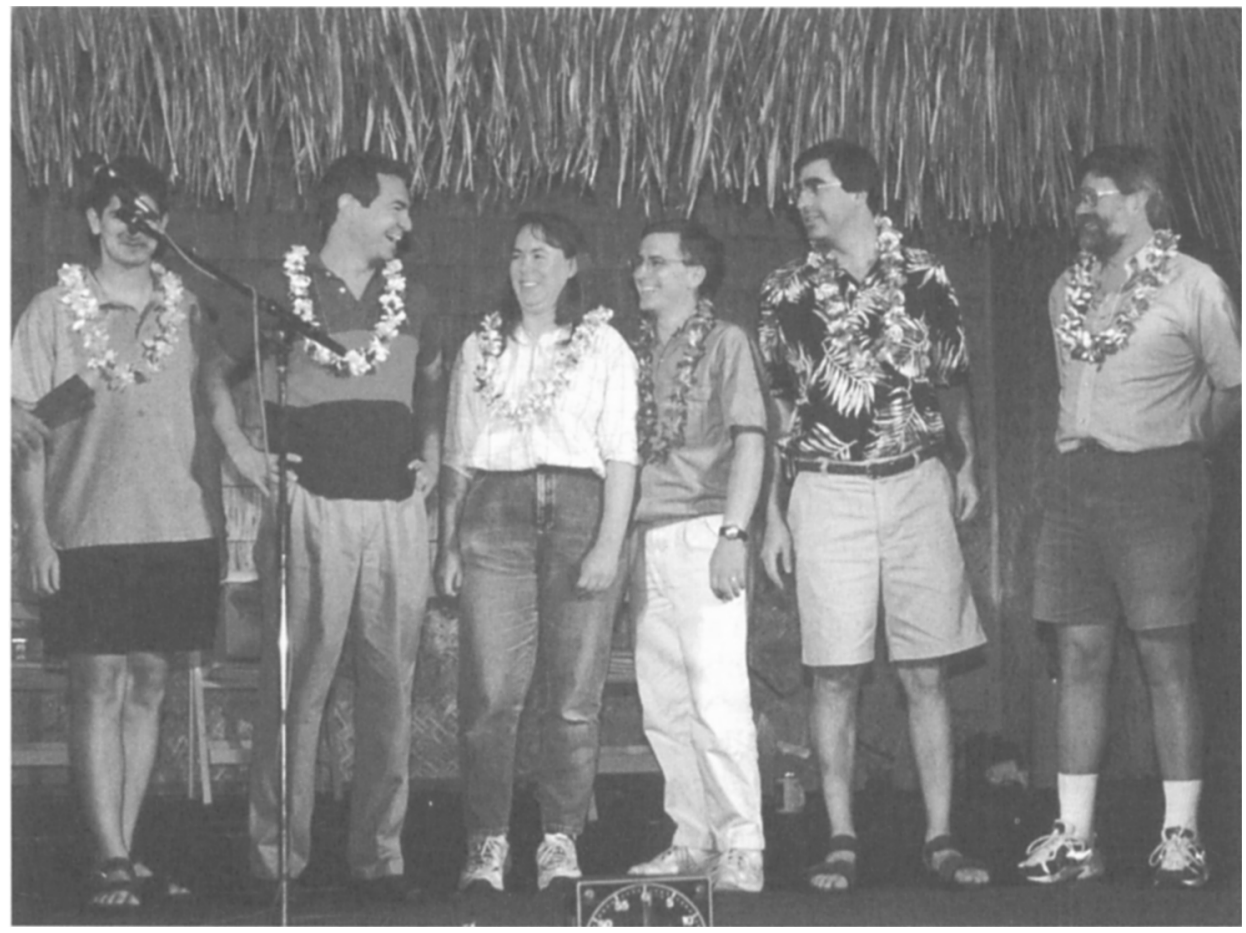

Runner-up team in the volleyball contest. From left to right: Chris Gelino, Nick Siegler, Denise Stephens, Thomas Stephens, Scott Wolk, and Fred Walter. 